\title{
Nudging: A Very Short Guide
}

\section{Citation}

Cass R. Sunstein, Nudging: A Very Short Guide, 37 J. Consumer Pol'y 583 (2014).

\section{Permanent link}

http://nrs.harvard.edu/urn-3:HUL.InstRepos:16205305

\section{Terms of Use}

This article was downloaded from Harvard University's DASH repository, and is made available under the terms and conditions applicable to Other Posted Material, as set forth at http:// nrs.harvard.edu/urn-3:HUL.InstRepos:dash.current.terms-of-use\#LAA

\section{Share Your Story}

The Harvard community has made this article openly available.

Please share how this access benefits you. Submit a story.

Accessibility 


\title{
Preliminary draft 9/22/14 \\ all rights reserved \\ Preferred citation: \\ 37 J. CONSUMER Pol'y 583 (2014)
}

\section{Nudging: A Very Short Guide}

Cass R. Sunstein*

\begin{abstract}
This brief essay offers a general introduction to the idea of nudging, along with a list of ten of the most important "nudges." It also provides a short discussion of the question whether to create some kind of separate "behavioral insights unit," capable of conducting its own research, or instead to rely on existing institutions.
\end{abstract}

\section{Liberty-Preserving Approaches}

Some policies take the form of mandates and bans. For example, the criminal law forbids theft and assault. Other policies take the form of economic incentives (including disincentives), such as subsidies for renewable fuels, fees for engaging in certain activities, or taxes on gasoline and tobacco products. Still other policies take the form of nudges - liberty-preserving approaches that steer people in particular directions, but that also allow them to go their own way. In recent years, both private and public institutions have shown mounting interest in the use of nudges, because they generally cost little and have the potential to promote economic and other goals (including public health).

In daily life, a GPS is an example of a nudge; so is an "app" that tells people how many calories they ate during the previous day; so is a text message, informing customers that a bill is due or that a doctor's appointment is scheduled for the next day; so is an alarm clock; so is automatic enrollment in a pension plan; so are the default settings on computers and cell phones; so is a system for automatic payment of credit card bills and mortgages. In government, nudges include graphic warnings for cigarettes; labels for energy efficiency or fuel economy; "nutrition facts" panels on food; the "Food Plate," which provides a simple guide for healthy eating (see choosemyplate.gov); default rules for public assistance programs (as in "direct certification" of the eligibility of poor children for free school meals); a website like data.gov or data.gov.uk, which makes a large number of data sets available to the

${ }^{*}$ Robert Walmsley University Professor, Harvard University. Special thanks to Lucia Reisch, Maya Shankar, and Richard Thaler for valuable comments and suggestions, and to Thaler for many years of collaboration on these questions; none of them should be held responsible for any errors or infelicities here. 
public; and even the design of government websites, which list certain items first and in large fonts.

\section{A. Nudges Maintain Freedom of Choice}

It is important to see that the goal of many nudges is to make life simpler, safer, or easier for people to navigate. Consider road signs, speed bumps, disclosure of health-related or finance-related information, educational campaigns, paperwork reduction, and public warnings. When officials reduce or eliminate paperwork requirements, and when they promote simplicity and transparency, they are reducing people's burdens. Some products (such as cell phones and tablets) are intuitive and straightforward to use. Similarly, many nudges are intended to ensure that people do not struggle when they seek to interact with government or to achieve their goals.

It is true that some nudges are properly described as a form of "soft paternalism," because they steer people in a certain direction. But even when this is so, nudges are specifically designed to preserve full freedom of choice. A GPS steers people in a certain direction, but people are at liberty to select their own route instead. And it is important to emphasize that some kind of social environment (or "choice architecture"), influencing people's choices, is always in place. New nudges typically replace preexisting ones; they do not introduce nudging where it did not exist before.

\section{B. Transparency and Effectiveness}

Any official nudging should be transparent and open rather than hidden and covert. Indeed, transparency should be built into the basic practice. Suppose that a government (or a private employer) adopts a program that automatically enrolls people in a pension program, or suppose that a large institution (say, a chain of private stores, or those who run cafeterias in government buildings) decides to make healthy foods more visible and accessible. In either case, the relevant action should not be hidden in any way. Government decisions in particular should be subject to public scrutiny and review. A principal advantage of nudges, as opposed to mandates and bans, is that they avoid coercion. Even so, they should never take the form of manipulation or trickery. The public should be able to review and scrutinize nudges no less than government actions of any other kind.

All over the world, nations have become keenly interested in nudges. To take two of many examples, the United Kingdom has a Behavioral Insights Team (sometimes called the "Nudge Unit"), and the United States has a White House Social and Behavioral Sciences Team. The growing interest in nudges stems from the fact that they usually impose low (or no) costs, because they sometimes deliver prompt results (including significant economic savings), because they maintain freedom, and because they can be highly effective. In some cases, nudges have a larger impact than more expensive and more coercive tools. For example, default rules, 
simplification, and uses of social norms have sometimes been found to have even larger impacts than significant economic incentives.

In the context of retirement planning, automatic enrollment has proved exceedingly effective in promoting and increasing savings. In the context of consumer behavior, disclosure requirements and default rules have protected consumers against serious economic harm, saving many millions of dollars. Simplification of financial aid forms can have the same beneficial effect in increasing college attendance as thousands of dollars in additional aid (per student). Informing people about their electricity use, and how it compares to that of their neighbors, can produce the same increases in conservation as a significant spike in the cost of electricity. If properly devised, disclosure of information can save both money and lives. Openness in government, disclosing both data and performance, can combat inefficiency and even corruption.

\section{The Need for Evidence and Testing}

For all policies, including nudges, it is exceedingly important to rely on evidence rather than intuitions, anecdotes, wishful thinking, or dogmas. The most effective nudges tend to draw on the most valuable work in behavioral science (including behavioral economics), and hence reflect a realistic understanding of how people will respond to government initiatives. But some policies, including some nudges, seem promising in the abstract, but turn out to fail in practice. Empirical tests, including randomized controlled trials, are indispensable. Bad surprises certainly are possible, including unintended adverse consequences, and sensible policymakers must try to anticipate such surprises in advance (and to fix them if they arise). Sometimes empirical tests reveal that the planned reform will indeed work - but that some variation on it, or some alternative, will work even better.

Experimentation, with careful controls, is a primary goal of the nudge enterprise. Fortunately, many nudge-type experiments can be run rapidly and at low cost, and in a fashion that allows for continuous measurement and improvement. The reason is that such experiments sometimes involve small changes to existing programs, and those changes can be incorporated into current initiatives with relatively little expense or effort. If, for example, officials currently send out a letter to encourage people to pay delinquent taxes, they might send out variations on the current letter and test whether the variations are more effective.

\section{Ten Important Nudges}

Nudges span an exceedingly wide range, and their number and variety are constantly growing. Here is a catalogue of ten important nudges - very possibly, the most important for purposes of policy - along with a few explanatory comments.

(1) default rules (e.g., automatic enrollment in programs, including education, health, savings) 
Comment: Default rules may well be the most effective nudges. If people are automatically enrolled in retirement plans, their savings can increase significantly. Automatic enrollment in health care plans, or in programs designed to improve health, can have significant effects. Default rules of various sorts (say, double-sided printing) can promote environmental protection. Note that unless active choosing (also a nudge) is involved, some kind of default rule is essentially inevitable, and hence it is a mistake to object to default rules as such. True, it might make sense to ask people to make an active choice, rather than relying on a default rule. But in many contexts, default rules are indispensable, because it is too burdensome and time-consuming to require people to choose.

(2) simplification (in part to promote take-up of existing programs)

Comment: In both rich and poor countries, complexity is a serious problem, in part because it causes confusion (and potentially violations of the law), in part because it can increase expense (potentially reducing economic growth), and in part because it deters participation in important programs. Many programs fail, or succeed less than they might, because of undue complexity. As a general rule, programs should be easily navigable, even intuitive. In many nations, simplification of forms and regulations should be a high priority. The effects of simplification are easy to underestimate. In many nations, the benefits of important programs (involving education, health, finance, poverty, and employment) are greatly reduced because of undue complexity.

(3) uses of social norms (emphasizing what most people do, e.g., "most people plan to vote" or "most people pay their taxes on time" or "nine out of ten hotel guests reuse their towels")

Comment: One of the most effective nudges is to inform people that most others are engaged in certain behavior. Such information is often most powerful when it is as local and specific as possible ("the overwhelming majority of people in your community pay their taxes on time"). Use of social norms can reduce criminal behavior and also behavior that is harmful whether or not it is criminal (such as alcohol abuse, smoking, and discrimination). It is true that sometimes most or many people are engaging in undesirable behavior. In such cases, it can be helpful to highlight not what most people actually do, but instead what most people think people should do (as in, "90 percent of people in Ireland believe that people should pay their taxes on time").

(4) increases in ease and convenience (e.g., making low-cost options or healthy foods visible) 
Comment: People often make the easy choice, and hence a good slogan is this: "make it easy." If the goal is to encourage certain behavior, reducing various barriers (including the time that it takes to understand what to do) is often helpful. Resistance to change is often a product not of disagreement or of skepticism, but of perceived difficulty - or of ambiguity. A supplemental point: If the easy choice is also fun, people are more likely to make it.

(5) disclosure (for example, the economic or environmental costs associated with energy use, or the full cost of certain credit cards - or large amounts of data, as in the cases of data.gov and the Open Government Partnership, see opengovernmentpartnership.org)

Comment: The American Supreme Court Justice Louis Brandeis said that "sunlight is the best of disinfectants," and disclosure can make both markets and governments much "cleaner." For consumers, disclosure policies can be highly effective, at least if the information is both comprehensible and accessible. Simplicity is exceedingly important. (More detailed and fuller disclosure might be made available online for those who are interested in it.) In some settings, disclosure can operate as a check on private or public inattention, negligence, incompetence, wrongdoing, and corruption. The Open Government Partnership, now involving sixty-four nations, reflects a worldwide effort to use openness as a tool for promoting substantive reform.

(6) warnings, graphic or otherwise (as for cigarettes)

Comment: If serious risks are involved, the best nudge might be a private or public warning. Large fonts, bold letters, and bright colors can be effective in triggering people's attention. A central point is that attention is a scarce resource, and warnings are attentive to that fact. One virtue of warnings is that they can counteract the natural human tendency toward unrealistic optimism and simultaneously increase the likelihood that people will pay attention to the long-term. There is a risk, however, that people will respond to warnings by discounting them ("I will be fine"), in which case it would make sense to experiment with more positive messages (providing, for example, some kind of reward for the preferred behavior, even if the reward is nonmonetary, as in apps that offer simple counts and congratulations). Research also shows that people are far less likely to discount a warning when it is accompanied by a description of the concrete steps that people can take to reduce the relevant risk ("you can do X and Y to lower your risk").

(7) precommitment strategies (by which people commit to a certain course of action)

Comment: Often people have certain goals (for example, to stop drinking or smoking, to engage in productive activity, or to save money), but their behavior falls short of those goals. If people precommit to engaging in certain 
action - such as a smoking cessation program - they are more likely to act in accordance with their goals. Notably, committing to a specific action at a precise future moment in time better motivates action and reduces procrastination.

(8) reminders (for example, by email or text message, as for overdue bills and coming obligations or appointments)

Comment: People tend to have a great deal on their minds, and when they do not engage in certain conduct (for example, paying bills, taking medicines, or making a doctor's appointment), the reason might be some combination of inertia, procrastination, competing obligations, and simple forgetfulness. A reminder can have a significant impact. For reminders, timing greatly matters; making sure that people can act immediately on the information is critical (especially in light of the occasional tendency to forgetfulness). A closely related approach is "prompted choice," by which people are not required to choose, but asked whether they want to choose (for example, clean energy or a new energy provider, a privacy setting on their computer, or to be organ donors).

(9) eliciting implementation intentions ("do you plan to vote?")

Comment: People are more likely to engage in activity if someone elicits their implementation intentions. With respect to health-related behavior, a simple question about future conduct ("do you plan to vaccinate your child?") can have significant consequences. Emphasizing people's identity can also be effective ("you are a voter, as your past practices suggest").

(10) informing people of the nature and consequences of their own past choices ("smart disclosure" in the US and the "midata project" in the UK)

Comment: Private and public institutions often have a great deal of information about people's own past choices - for example, their expenditures on health care or on their electric bills. The problem is that individuals often lack that information. If people obtain it, their behavior can shift, often making markets work better (and saving a lot of money).

\section{Institutionalizing Nudges: Two Approaches}

What is the best method for implementing nudges? It is certainly possible to rely entirely on existing institutions. We could imagine a system in which an understanding of nudges is used by current officials and institutions, including leaders at the highest levels. For example, the relevant research could be enlisted by those involved in promoting competitiveness, environmental protection, public safety, consumer protection, and economic growth - or in reducing private and public corruption and combating poverty, infectious diseases, and obesity. Focusing 
on concrete problems rather than abstract theories, officials with well-established positions might be expected to use that research, at least on occasion.

If the relevant officials have both knowledge and genuine authority, they might be able to produce significant reforms, simply because they are not akin to a mere research arm or a think-tank. (Even a single person, if given the appropriate authority and mission, could have a large impact.) On one model, the relevant officials would not engage in new research, or at least not in a great deal of it. They would build on what is already known (and perhaps have formal or informal partnerships with those in the private sector who work on these issues). In an important sense, this approach is the simplest, because it does not require new offices or significant additional funding, but only attention to the relevant issues and a focus on the right appointments. In the United States, this kind of approach has proved highly successful, with the adoption of numerous nudges.

A quite different approach would be to create a new institution - such as a behavioral insights team or a "nudge unit" of some sort (as in the United Kingdom, the United States, and increasingly many nations). Such an institution could be organized in different ways, and it could have many different forms and sizes. On a minimalist model, it would have a small group of knowledgeable people (say, five), bringing relevant findings to bear and perhaps engaging in, or spurring, research on their own. On a more ambitious model, the team could be larger (say, thirty or more), engaging in a wide range of relevant research. A behavioral insights team could be created as a formal part of government (the preferred model, to ensure real impact) or could have a purely advisory role.

Whatever its precise form, the advantage of such an approach is that it would involve a dedicated and specialized team, highly informed and specifically devoted to the relevant work, and with expertise in the design of experiments. If the team could work with others to conduct its own research, including randomized controlled trials, it might be able to produce important findings (as has in fact been done in the United Kingdom and the United States, and similar efforts are occurring elsewhere). The risk is that such a team would be akin to an academic adjunct, a kind of outsider, without the ability to power or ability initiate real reform. Authority greatly matters. The United Kingdom has had the most experience with this kind of approach, and it has succeeded in part because it has enjoyed high-level support and access.

In this domain, one size does not fit all, but it is noteworthy that a growing number of nations have concluded that it is worthwhile to have a dedicated team. Of course the two approaches might prove complementary. 